\title{
VERDAD Y FICCIÓN. LITERATURA Y POLÍTICA
}

\section{TRUTH AND FICTION. LITERATURE AND POLITICS}

\author{
Darío Villanueva \\ Real Academia Española \\ Universidad de Santiago de Compostela
}

\section{ABSTRACT}

The logical status of a literary statement is different from that of a standard act of communication, both written and oral. This distinction refers to two basic principles of linguistic pragmatics, that of cooperation and that of sincerity. When we communicate with someone, we not only tend to believe what they tell us, but reject the idea that their behavior in this regard might be the opposite. By contrast, in reading a novel, we voluntarily assumed the «willing suspension of disbelief» as defined by Coleridge. This is, in short, the fundamental difference between fiction and reality or truth. But such a distinction, so clear, can be the subject of revisions, contradictions and manipulations, the incidence of which is intensified when from the literary universe we make the leap to the use of language in political communication

Key words: Postruth, fiction, pragmatics, postdemocracy, posmodernity 


\section{RESUMEN}

El estatuto lógico de un enunciado literario es diferente al que le corresponde a un acto de comunicación estándar, tanto escrito como oral. Tal distinción remite a dos principios básicos de la Pragmática lingüística, el de cooperación y el de sinceridad. Cuando nos comunicamos con alguien, no solo tendemos a creer lo que nos dice, sino que rechazamos la idea de que su conducta a este respecto pudiera ser la opuesta. Por el contrario, al leer una novela, asumimos voluntariamente la «willing suspensión of disbelief» así definida por Coleridge. Se trata, en definitiva, de la diferencia fundamental existente entre ficción y realidad o verdad. Pero semejante distinción, tan clara, puede ser objeto de revisiones, contradicciones y manipulaciones, cuya incidencia se intensifica cuando desde el universo literario damos el salto a la utilización del lenguaje en la comunicación política

Palabras clave: Posverdad, ficción, pragmática lingüística, posdemocracia, posmodernidad

Fecha de recepción: 11 de octubre de 2021.

Fecha de aceptación: 11 de noviembre de 2021.

Cómo citar: Villanueva, Darío (2021): «Verdad y ficción. Literatura y política», en Actio Nova: Revista de Teoría de la Literatura y Literatura Comparada, 5: 458-489.

DOI: https://doi.org/10.15366/actionova2021.5.019 
A la hora de investigar sobre el realismo pude llegar a la conclusión de que este efecto no está tanto en la voluntad del escritor o en la propia configuración del contenido y la forma de la obra, sino en la recepción del texto y la respuesta a él por parte del lector. No se trata -escribía yo en mi libro de 1992, traducido al inglés en 1997- de un problema de la génesis de la obra, de la realidad que estaría en su origen; tampoco, exclusivamente, del lenguaje o la estructura literaria. Lo fundamental sigo pensando que reside en la posibilidad, más o menos plausible, de un lector o una lectura intencionalmente realista. Y esta se produce cuando proyectamos nuestro sesgo confirmatorio basado en nuestra experiencia propia de la realidad sobre el mundo de ficción que, por ejemplo, la novela nos propone. Y así, en la tercera edición de mis Teorías del realismo literario añadí a modo de lema unos versos de mi recordado amigo el poeta Ángel González:

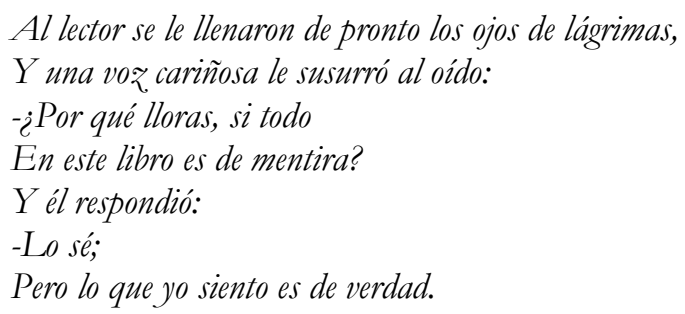

Una escritora y profesora universitaria, Susan Fromberg Schaeffer, ha aportado su propia experiencia de cómo funciona este sesgo generador de una poderosa ilusión referencial entre el público. Su novela Anya sobre los desastres de la segunda guerra mundial creó entre sus lectores de todo el mundo -escribe ella- tal «ilusión de absoluta autenticidad» que llegó a recibir cartas en polaco de supervivientes de la contienda pidiéndole información sobre personas concretas, una llamada telefónica de una mujer de Australia convencida de que la novelista norteamericana era su hermana perdida entonces, y los propios editores tardaron en aceptar que no era europea y no tenía cuando la novela se publicó en 1974 por lo menos cincuenta años, sino treintaicinco.

Sin embargo, sabemos bien que el estatuto lógico de un enunciado literario, narrativo, teatral o lírico, es muy diferente al que le corresponde a un enunciado común, perteneciente a un acto de comunicación estándar, tanto escrito como oral. Tal distinción nos remite a dos principios básicos de la Pragmática lingüística, que Herbert Paul Grice resume en dos principios: el de cooperación y el de sinceridad. Cuando nos comunicamos con alguien, no solo tendemos a creer lo que nos dice como cierto, sino que rechazamos la 
idea de que su conducta a este respecto pudiera ser la opuesta. Eso nos vuelve sumamente vulnerables, por lo que es necesario habilitar «gatillos»-triggers en el texto inglés de Timothy Levine (2020)- que desencadenen en nosotros mecanismos de defensa para la detección de las mentiras. Por el contrario, cuando leemos, por ejemplo, una novela, asumimos voluntaria y gozosamente la «willing suspensión of disbelief» que en acuñó en brillante frase Samuel Taylor Coleridge y nuestro Alfonso Reyes tradujo como la «voluntaria suspensión del descreimiento». Se trata, en definitiva, de la diferencia fundamental existente entre ficción y realidad o verdad.

Pero semejante distinción, aparentemente tan clara e irrebatible, puede ser objeto de revisiones, disputas y manipulaciones, cuya incidencia se intensifica desde el momento en que desde el universo de la literatura damos el salto a una utilización concreta del lenguaje: la que se da en la comunicación política. Junto a la evidencia de que por naturaleza somos truth-biased, personas inclinadas o «sesgadas» hacia la verdad, los psicólogos sociales han estudiado también la influencia de ciertos cognitive biases, de los prejuicios o predisposiciones que debemos admitir influyen poderosamente en nosotros, aunque la aceptación de ello nos revele que somos menos racionales de lo que pensamos o nos gustaría ser. Pulsiones que, además, pueden ser manipuladas por otros. De hecho, Lee McIntyre (2018) considera a Joseph Goebbels un maestro en manejar algunos de estos sesgos cognitivos como la source amnesia -la incapacidad para recordar donde, cuando y como adquirimos la información de hechos que sin embargo retenemos en la memoria- o el repetition effect. Expertos en psicología social nos ilustran asimismo acerca del backfire effect, que no es otra cosa que nuestro proverbial sostenella y no enmendalla. Una convicción basada en pulsiones ideológicas o políticas no cambia por la evidencia factual. Y también es objeto de estudio el llamado Dunning-Kruger effect, un sesgo cognitivo por el cual los demasiado estúpidos no solo no son capaces de reconocer que lo son, sino que se crecen.

Por ese sesgo de confirmación o sesgo confirmatorio renunciamos al razonamiento inductivo a favor de una tendencia cognitiva que favorece la interpretación de los hechos conforme a nuestras informaciones y suposiciones previas, imbuidas de nuestra emocionalidad. Seguimos así las pautas de un pensamiento ilusorio que nosotros mismos nos hemos dado y que concede prioridad absoluta a nuestras creencias personales frente a evidencias contrarias. Funciona, en consecuencia, una especie de extraño mecanismo de profecía autocumplida, que incluye una interpretación sesgada de una información previamente 
recabada selectivamente, un no menos decisivo «sesgo de memoria», que Freud nos ayudaría a entender.

En consecuencia, nuestras actitudes ante un hecho, una realidad y su interpretación se polarizan ante versiones diferentes, para confirmar nuestro parti pris. Y se caracteriza también tal estado de nuestra mente por la persistencia de creencias desacreditadas. Y por la correlación ilusoria entre eventos, germen de las teorías conspirativas. Pensemos, a este respecto, en el movimiento del rechazo a las vacunas en sociedades desarrolladas, o en el dato de que casi el $50 \%$ de los ciudadanos de USA desdeñan las teorías evolucionistas inspiradas en Darwin y son decididos creyentes en el creacionismo divino del Génesis bíblico.

Existe un neologismo en inglés, truthiness, atribuido a la invención del cómico Stephen Colbert, que fue en 2005 la «palabra del año» para The American Dialect Society y en 2006 para el diccionario Merriam-Webster. Colbert empezó a utilizarla en sus programas de televisión para satirizar la manipulación de los recursos retóricos y emocionales en el discurso político en la época de George W. Bush. De esta manera designaba el procedimiento sicológico por el que un individuo acomodaba la verdad a su prejuicio, intuición o, simplemente, bienestar emocional sin reparar en la fuerza de los hechos, la lógica o el mero escrutinio racional. Trutbiness -no hay hasta el momento traducción al español- sería así, según Colbert, «lo que tú quieres que sean los hechos, a diferencia de lo que los hechos son (...) Porque, damas y caballeros, ¡de aquí viene la verdad! ¡De las tripas!».

Mas, precisamente, encuentro en la literatura narrativa una magnífica muestra de este sesgo confirmatorio. En este caso es un cuento de Alfonso Rodríguez Castelao (1999) titulado «O retrato». En esta narración escrita en gallego en 1922 y publicada por primera vez en una revista en 1927, un médico alejado de la práctica profesional y consumado dibujante, como lo fue el propio escritor, es reclamado por el tabernero Melchor no para que sane a su hijo moribundo, sino para que le haga su último retrato, que él fotógrafo no puede realizar por falta de magnesio.

Conmovido por la angustia en tal trance de su amigo Melchor, que lo convence con el argumento de que «dous riscos de vostede nun papel e xa poderéi ollar para sempre a cariña do meu neno», el narrador comienza a trazar los rasgos del niño, tal y como lo ve, agonizante, pero el padre, que sigue atentamente su trabajo, se desespera por el resultado: «Pola ialma dos seus difuntos, non mo retrate así. Non lle poña esa cara tan encoveirada [cadavérica] e tan triste». Y añade que el dibujante bien sabía cómo era su rapaciño, que hiciese memoria y lo dibujase riendo. Entendido el mensaje, el médico retratista dibuja «un neno 
imaxinario. Inventéi un neno moi bonito, moi bonito: un anxo de retablo barroco, a sorrir». Y el padre ve aliviada su pena, aunque el rapaz ya ha muerto. El dibujo fúnebre e imaginario estará ya para siempre sobre la cómoda de su alcoba, y cada vez que el tabernero lo mire le hará exclamar: «Tiven moitos fillos, pero o máis bonito de todos foi o que me morréu. Velahí está o retrato que non minte».

A la teoría de estos sesgos, que tanto influyen en nuestra ilimitada capacidad de admitir como creíbles tantas posverdades, proporcionada por la psicología social, creo que es de interés adjuntar las aportaciones de un lingüista y psicólogo cognitivo, George Lakoff (2019), acerca de los «marcos mentales» (en inglés, el framing) y el pensamiento metafórico que nos proporcionan efectivamente los alibís más convenientes para nuestra comprensión personal del mundo.

En nuestro inconsciente cognitivo actúan como filtro determinados marcos que nos ayudan a dotar de sentido a los estímulos que nos llegan del exterior. Para ello, discriminan entre la información recibida aquella que encaja en nuestros parámetros personales de todo tipo (carácter, sensibilidad, sexo, cultura, religión, ideología, intereses económicos, etc.) y la que no, por extemporánea, incómoda, desequilibrante o subversiva. Cuando la información que recibimos (los datos) no se conforma a los marcos inscritos en nuestro cerebro, nos quedamos con los marcos e ignoramos los hechos. Tras superar ese filtro, interiorizamos una parte de información y rechazamos otra.

En consecuencia, es fácil concluir que la activación de esos marcos mentales de los ciudadanos a favor de propuestas políticas concretas es hoy en día fundamental en nuestras democracias (o ¿quizás posdemocracias?). Los electores votan desde sus sesgos y marcos, y no solo por el ejercicio consciente de la razón. El éxito de un determinado partido depende, pues, en gran medida de su capacidad para adecuar sus propuestas a aquellas pulsiones que están latentes entre los votantes, pero que se pueden activar si se ponen en juego estrategias perfectamente estudiadas para ello.

El libro más conocido de Lakoff (2019) sobre lenguaje y debate político, publicado originariamente en 2004, menciona en su título a un elefante, que es el emblema del partido republicano en USA. Y esto porque el autor considera que este partido, por aquellos años, por contar con expertos hábiles al respecto había sabido mucho mejor que los demócratas adecuar sus propuestas e intereses políticos a los marcos mentales de los estadounidenses. Un magnífico ejemplo de tal acomodo fue la introducción en el discurso sobre el estado de la nación de una fraseología que subliminalmente apuntaba en una dirección favorable para 
que la opinión pública aceptara la invasión de Irak que se produciría en marzo de 2003. George W. Bush argumentó que su país no necesitaba «ningún justificante de permiso» para defenderse. Esta expresión remitía a la autorización que los alumnos de enseñanza media necesitan para determinados movimientos dentro de los institutos. Los Estados Unidos daba a entender Bush jr.- no solo es un adulto en el concierto de las naciones, sino la máxima potencia en el mundo, y su posición lo identifica con la del padre estricto pero justo y, sobre todo, protector, que sabe cuándo debe actuar, cómo y por qué en beneficio de la familia (léase, el orden internacional). Sin «justificantes de permiso».

En cuanto el empleo que propongo, en este contexto, del sustantivo español patraña, su razón de ser nace de que debemos reparar no solo en las fake-news, los bulos, sino también en las fake-stories, construcciones verbales y narrativas más desarrolladas a las que atiende en 2007 Christian Salmon en su libro sobre «la máquina de fabricar historias y formatear las mentes» titulado con una palabra inglesa: Storytelling. Aquí Sorytelling es tanto como contar un cuento chino; una patraña.

De nuevo la sociedad norteamericana, como en tantas cosas más tal y como viene ocurriendo desde el final de la segunda guerra mundial, marca la pauta de un fenómeno que no es, por supuesto, exclusivo de ella, pero al que sin embargo le ha puesto nombre, y lo exporta con éxito ecuménico. Allí existe una National Storytelling Network que organiza más de doscientos festivales «narrativos» cada año, eclosión en la que desde 1995 ha tenido una influencia incuestionable la generalización en el uso de la red de redes. La Galaxia Internet, que utilizando la terminología macluhiana vendría después de la Galaxia de la comunicación eléctrica, presunto verdugo de la Galaxia Gutenberg, es, por lo tanto, eficaz aliada de lo que Salmon llama narrative turn. Este «giro» da paso al «pensamiento narrativo» que tiene más de lo segundo que de lo primero -menguada racionalidad, más emocionalidad-, y lleva al «imperialismo narrativo» que se impone cuando «el imperio ha confiscado el relato», algo que como mencionaremos más adelante era perfectamente asumido por «fontaneros» de George W. Bush como Karl Rove.

Si la crisis de la posmodernidad significó la quiebra de los llamados «grandes relatos legitimadores -por ejemplo, las religiones (salvo el Islam para sus fieles), el pensamiento fuerte, las ideologías-, lo que se impone ahora es el recurso a los pequeños relatos, a todo lo que busque empatizar con los «marcos mentales» -el framing de Lakoff- de los ciudadanos, de modo que, por caso, las campañas presidenciales norteamericanas, según Salmon, se han reducido a «la batalla de las historias, y no el debate de las ideas». Constituyen un gran festival 
narrativo, algo así como un duelo vertiginoso de relatos. Las anécdotas sustituyen a los datos y a las estadísticas en los discursos de los candidatos, y sus posverdades desplazan a la realidad de los hechos. Por no practicar estas estrategias los partidarios del Remain perdieron el referéndum del Brexit.

En consecuencia, la clave para lograr el poder está en incidir sobre las emociones y los marcos o sesgos mentales de los votantes, considerados como el público que asiste a un espectáculo. Miembros de una sociedad mediatizada hasta la extenuación, bombardeada por rumores, falsas noticias, manipulaciones, bulos y patrañas, que en la red se caracterizan además por su viralidad. Todo el despliegue de la posverdad. Nada, por supuesto, de argumentos racionales, sino relatos, historias. La apoteosis de la civilización del espectáculo retratada por Mario Vargas Llosa (2012).

Salmon, por su parte, ve el despacho oval (y el espectacular y fotogénico Air Force One, añadiría yo) como un plató en el que se rueda le película de la presidencia, y «el poder ejecutivo se convierte en un poder de ejecución, de realización -en el sentido cinematográficodel guion presidencial». Y en la consolidación de este modelo, no podría tener rival un presidente que fue actor, Ronald Regan, la mayoría de las historias por él contadas solo tenían un pequeño problema: eran falsas.

Era el suyo una suerte de «pensamiento narrativo», en el que la emocionalidad desplazaba por completo a la veracidad. Maestro en esta usurpación política de la narración, Ronald Reagan, definido por Salmon como «el mejor storyteller de la historia política del último medio siglo», gobernó a base de anécdotas, muchas ficticias. Puede que la tendencia venga de antes, del Watergate, pero lo que resulta indudable es que los republicanos estadounidenses, desde Nixon y Reagan hasta Bush jr. y Trump, han conseguido activar, en una parte significativa de la población, los marcos mentales que más les convienen, entre ellos el del Estado como «padre estricto» que define reglas de conducta, que castiga y educa con firmeza cuando la situación lo requiere, cuya última expresión la encontramos en la mano dura para imponer el orden que el presidente tuitero esgrimió durante el verano de 2020 en contra las protestas antirracistas frente a la presunta debilidad de su opositor Joe Biden. Con anterioridad, habían movilizado entre sus votantes representaciones como la del individuo expoliado por el Estado (para justificar la rebaja de los impuestos), el carácter sacrosanto del matrimonio (para oponerse al matrimonio homosexual) o, incluso, las libertades consagradas por el Bill of Rigths (para negar la adopción de medidas de prevención individual y colectiva contra la COVID-19). 
En esta nueva era narrativa de las posdemocracias, el príncipe ya no tiene a su vera a validos y consejeros, sino a un nuevo tipo de asistentes áulicos, que pueden parecer una fusión baciyélmica de profeta y gurú, pero que en realidad son técnicos en el conocimiento de los marcos mentales y de los sesgos de confirmación de los electores y dueños de las más sofisticadas estrategias narrativas, auténticos prestidigitadores de la posverdad.

En inglés los denominan spin doctors, y su doctorado lo es en storytelling. Tienen siempre a su disposición relatos, bulos y patrañas -《invención urdida con propósito de engañan» en el DLE-, que les ayudan a urdir y difundir los story spinners, los obreros de una factoría propagandística que modifica el modus operandi tradicional de los «relaciones públicas». Estos elaboraban una presentación creativa de los hechos para favorecer los intereses de los individuos o entidades para los que trabajaban. Aquellos, los story spinners, son peritos en manipulación, en hacer que una idea no probada o simplemente falsa sea aceptada como verdadera, en emplear sistemáticamente eufemismos y en ocultar las malas noticias. Cuando el atentado de las torres gemelas, el jefe de prensa del gobierno británico, que tuvo que dimitir después, afirmo, por ejemplo, que aquel era un buen día para lanzar informaciones negativas que se desease enterrar. De tal modo que la vida política se sustente en una narración, en un relato o serie de relatos engañosos, que tiendan a reemplazar la tradicional asamblea deliberativa de los ciudadanos, y la fluidez de la esfera púbica constituida en torno a ellos, por una audiencia cautiva, una comunidad virtual y ficcional. Si lo deliberativo exigía argumentación, razonabilidad y verdad, al relato le basta y le sobra con la emocionalidad, los bulos, las patrañas, la posverdad.

A este respecto, es imprescindible insistir en destacadas facetas de la personalidad del expresidente norteamericano Ronald Reagan, que ocupó la Casa Blanca entre 1981 y 1989. Tal y como incluí, ya en 2008, en mi libro publicado en México Las fábulas mentirosas. Lectura, realidad, ficción, nueve años antes había provocado cierto escándalo la aparición de una nueva biografía suya, titulada Ducht (el apodo juvenil de Reagan) y escrita por Edmund Morris, que ya había ganado un Pulitzer con otra biografía, entonces de Theodor Roosevelt.

En su libro, Morris revela que la famosa «Iniciativa de Defensa Estratégica» del expresidente norteamericano, que los medios de comunicación enseguida denominaron «La Guerra de las Galaxias», estuvo basada en Una Princesa de Marte, uno de los libros de ciencia ficción de Edgard Rice Burroughs a quien Reagan admiraba.

Nada de nuevo hay en aquella revelación del biógrafo Morris, que no hace sino ratificar los asombrosos episodios contados por Lou Cannon (1991) en la obra President 
Reagan. The Role of a Lifetime, aparecida a principios de los noventa del siglo pasado. A lo largo de sus campañas electorales de 1976 y 1980, Reagan, con la habilidad retórica que le caracterizaba, incluida una eficaz actuación (actio) de viejo actor de Hollywood, repitió varias veces en sus discursos un relato que hizo también el 12 de diciembre de 1983 ante la convención anual de la Congressional Medal of Honor Society celebrada en Nueva York.

Para enardecer el sentido patriótico de su auditorio, de antemano entregado, lo que constituyó uno de los ejes centrales de su política presidencial sumamente interesada en vencer lo que Noam Chomsky denominaba «el síndrome de Vietnam», resultado de la derrota humillante en aquella guerra, Reagan narró un emocionante caso de heroísmo. Un bombardero B-17, en misión sobre Alemania durante la Segunda Guerra Mundial, fue alcanzado por los antiaéreos, con el resultado de que el artillero de la torreta quedara herido sin que sus compañeros de tripulación pudieran retirarlo de su posición. Al cruzar el canal, el avión empezó a perder altura y el comandante ordenó saltar. El joven herido, viéndose condenado a estrellarse contra el mar, comenzó a llorar y entonces el comandante se sentó junto a él, lo cogió de la mano y le dijo: Never mind, son, we'll ride it down together («Tranquilo, hijo, nos hundiremos juntos»). Reagan, en su mitin, mencionó textualmente esta frase, y añadió que el héroe había recibido póstumamente la «Congressional Medal of Honon».

Pero he aquí que un periodista del New York Daily News, Lars-Erik Nelson, se tomó la molestia de consultar los registros de la citada condecoración, que se concedió 434 veces durante la segunda guerra mundial, y no encontró nada referente al caso por Reagan tan ponderado. Y cuando comentó este sorprendente hecho en su columna periodística, uno de sus lectores le escribió que el episodio recordaba una escena de la película de 1944 Wings and a prayer, dirigida por Henry Hathaway y protagonizada por Dana Andrews. Allí el piloto de un avión de la Navy encargado de tirar torpedos en el Pacífico Sur decide heroicamente acompañar hasta el final a su operador de radio herido diciéndole: We'll take this ride together («Haremos este camino juntos»), frase que se había quedado prendida en la memoria del joven Reagan. Cuando Nelson llevó el asunto hasta el gabinete de la Casa Blanca se encontró con una bizarra respuesta del portavoz Larry Speakes: «If you tell the same story five times, it's true».

Si cuentas una misma historia cinco veces, pasa a ser verdadera; argumento semejante al de Goebbels o al que se le atribuye a Bertrand Russell cuando afirmaba que los lectores de periódico suelen confundir la verdad con el cuerpo de letra doce. 
$\mathrm{Al}$ margen de cualquier valoración política, considero a Ronald Reagan una de las figuras semióticamente más interesante de la posmodernidad. Como sus biografías documentan, el que luego sería por dos veces Presidente de los Estados Unidos se hizo un ávido consumidor de ciencia-ficción durante su etapa de Hollywood, época en la que estuvo especialmente interesado en uno de los temas favoritos del género: la invasión de nuestro globo por alienígenas, lo que reclamaba una unión de todos los terrícolas para defenderse dejando a un lado las minucias de nuestras diferencias de raza, religión e ideología.

Pues bien, cuando su primer encuentro en la cumbre, que tuvo lugar en Ginebra en 1985, Reagan sorprendió al presidente Mijail Gorbachov proponiéndole un tratado de cooperación militar entre la Unión Soviética y los Estados Unidos para el supuesto de que nuestro planeta fuese objeto de una invasión por parte de los extraterrestres. Posteriormente se comprobó que esta moción no estaba en el memorándum que el gobierno norteamericano le había preparado a su presidente, sino que se debió a la iniciativa personal del propio Reagan. La respuesta de Gorbachov fue, asimismo, digna de un gran mandatario: declinó comprometerse, aduciendo que no tenía clara la posición de la teoría marxista-leninista acerca de la legitimidad de cooperar con los imperialistas contra una invasión interplanetaria. Reagan entendió, sin embargo, que esto era una disculpa de mal pagador, y así, al regresar a su país, contó la historia a los estudiantes de una high school de Maryland añadiendo que, en su valoración, con todo ello se había marcado un punto frente a Gorbachov y la Unión Soviética. Cuando tuvo noticia del episodio, Colin Powell, ya entonces diputado nacional consejero de seguridad, puso el grito en el cielo y se cuidó muy mucho de vigilar en adelante la aparición de referencias a los little green men, los «hombrecillos verdes» invasores alienígenas, en las intervenciones públicas del presidente. Identificó también la fuente de la proposición ginebrina a Gorbachov: el filme de ciencia-ficción estrenado en 1951 The Day the Earth Stood Still, dirigido por Robert Wise y protagonizado por Michael Rennie y Patricia Neal.

Lo que a mí más me preocupa es, precisamente, algo si no tan radical como la muerte de la realidad, sí al menos cercano a su apocalipsis. No obstante, estoy interesado, sobre todo, por el estudio de la suplantación de lo real por los signos de lo real, que, como veremos, no es cosa nueva, pero que sin duda puede adquirir en este nuevo siglo el carácter de una especie de sostenida maldición milenarista.

La falsedad y la falsificación están en la entraña del ser humano y siempre presentes en el funcionamiento de la sociedad. Somos, además, agentes pasivos de su pervivencia por mecanismos sicológicos profundos como aquel «sesgo de confirmación» que nos hace 
sumamente vulnerables a los engaños que confirman nuestros prejuicios, por no hablar de nuestra ilimitada capacidad para la estulticia, o incluso la idocia, contra la que nadie puede presumir que esté vacunado.

El anglicismo crudo fake, que tantas cosas puede englobar, utilizado frecuentemente en castellano con la forma compuesta «lo fake», identifica, revela y, en su caso, denuncia lo que Miguel Albero califica en un libro de 2020 como la invasión de lo falso. Y en su prólogo, el novelista Manuel Vilas relaciona, como yo también lo acabo de hacer en mi libro de 2021 Morderse la lengua. Corrección politica y posverdad, esa tendencia suicida de dudar de la verdad (Nietzsche y los suyos, hasta Foucault y Derrida) y confiar en la mentira (los posmodernos) con la «sociedad líquida» en que vivimos, «generadora de lo efímero», rehén de la corrección política que el escritor considera una «metástasis de fake». Y nos sorprende Vilas con una acertada conexión en la que quizás no habíamos caído: que la literatura, que era por su propia naturaleza «ficción», «se ha pasado a la verdad»: «Ahora la literatura tiene que contar verdades si quiere ser leída, nada de contar mentiras, eso déjamelo para el Facebook».

Una escuela o tendencia literaria destaca a este respecto: el New Journalism norteamericano, de Truman Capote, Norman Mailer, Tom Wolfe o Gay Talese, cultivadores de la llamada «novela sin ficción» o de reportajes periodísticos escritos con la técnica y el estilo de la mejor literatura narrativa. Con el antecedente inexcusable de Rodolfo Jorge Walsh, autor en 1957 de Operación Masacre, maestro español en este empeño es Javier Cercas, y su recreación del golpe de Estado del 23 de febrero de 1981 en Anatomía de un instante es un ejemplo comparable a los mejores de la literatura norteamericana. Viene muy a cuento recordar especialmente aquí otra de sus aportaciones, El impostor, de 2014, protagonizada por Enric Marco, un personaje egocéntrico y megalómano que se hizo pasar por superviviente de los campos de concentración nazis. Pero en los últimos tiempos está cobrando gran protagonismo otra expresión de lo mismo - «la literatura tiene que contar verdades si quiere ser leída, nada de contar mentiras»-, a la que precisamente Manuel Vilas contribuye de manera destacada con sus últimas obras.

Me refiero la autoficción, designada con este neologismo creado en 1977 por el crítico y novelista francés Serge Doubrovsky para referirse a su novela titulada Fils. En la literatura del país vecino, amén de algunos antecedentes en obras de Colette, Michel Butor, Léo Ferré, Violette Leduc, o Albertine Sarrazin, encontraría amplio eco en escritores como Guillaume Dustan, Nelly Arcan, Emmanuelle Pagano, Christine Angot, Chloé Delaume, Hervé Guibert o el propio Alain Robbe-Grillet. 
Define esta autoficción la mestura del sistema propio de la autobiografía (fusión entre tres entidades o instancias novelísticas: el autor empírico, real, que firma con su propio nombre; el narrador de la obra; y el protagonista de la historia que se cuenta, consistente precisamente en el relato de su propia vida) y la libertad imaginativa propia de la novela en lo que se refiere a los acontecimientos narrados y a sus protagonistas, que son personajes de ficción. Se da, en definitiva, la suma, aparentemente contradictoria, entre dos pactos de lectura opuestos: lo que Philippe Lejeune dio en denominar con éxito pacte autobiographique, y la «voluntaria suspensión del descreimiento» en que se basa el acto de leer una novela.

Trátase, pues, de sustituír aquellos dos pactos por otro (relativamente) novedoso, un pacto ambiguo por el que la enunciación del relato viene de una fuente autorial identificada con un autor real, conocido, con nombre y apellidos -por ejemplo, Manuel Vilas, pero lo que se nos cuenta se benefícia de todos los privilegios de la ficción novelesca en lo que se refiere a la invención de acontecimientos, situaciones, diálogos, personajes o avatares en general

El poder demiúrgico de la palabra como creadora -y no solo designadora- de la realidad, reconocido desde los Génesis judeocfristiano y maya-quiché, vio incrementada extraordinariamente su potencialidad con el desarrollo de la imprenta, que dio lugar a la aparición de los primeros best sellers de nuestra civilización, que fueron las novelas de caballerías. Ya en el siglo XVII, Pierre Daniel Huet, en su Lettre-traité sur l'origine des romans definía las novelas como «el arte de mentir agradablemente».

Aquel fenómeno -el relato de la ficción como realidad- se extendió velozmente por la Europa del Siglo XVI, de lo que no nos faltan múltiples testimonios. Mencionaré, en primer lugar, por su gran interés y su rareza, el «Raggionamento della Stampa», al comienzo de la segunda parte de I Marmi del Doni, academico peregrino, publicado en Venecia en 1552. Corroborarán enseguida las aprensiones del Doni numerosas muestras de la preocupación de los intelectuales y moralistas, que veían como una patraña adquiría frente al público estatuto de verdad simplemente por verse impresa. Francisco de Portugal cuenta, por ejemplo, cómo todas las mujeres de una casa recibieron un día al dueño desconsoladas porque había muerto el caballero andante Amadís, según acababan de leer. Y a propósito de ElQuijote, el moralista Melchor Cano dio ya cuenta de un cura que creía cierto todo lo narrado en este género de literatura no solo ficticia sino también fantástica porque de no ser así las autoridades no permitirían su divulgación impresa, el mismo argumento que en El Quijote 
Juan Palomeque contrapone al cura en I, 22, y el propio protagonista al canónigo toledano en I, 50 .

La «apariencia de verdad» de que habla don Quijote precisamente en ese mismo capítulo 50 de la Primera Parte, basada en detalles concretos y menudos, ya se puede colegir que se incrementa considerablemente en los medios audiovisuales, los cuales añaden a los signos verbales, que son simbólicos en cuanto no motivados, los iconos de los cuerpos, paisajes, objetos y sonidos de la realidad, ya sea ésta genuina o artificialmente reproducida.

Ya en 1669 un editor ambicioso, estimulado por el gran éxito comercial cosechado veintisiete años antes por el libro de François de Grenaille Nouveau recueil de lettres de dames tant anciennes que modernes desgaja de un volumen proyectado para contener la obra completa de Gabriel de Lavergne, señor de Guilleragues, las Lettres d'amour d'une religieuse escrites au chevalier de C., oficier françois en Portugal, que aparecen exentas, favoreciendo con su autobiografismo y su anonimato -como en el caso español del Lazarillo de Tormes- una lectura intencionalmente realista, no ficcional.

Lo que no fue, en su origen, sino un puro ardid comercial de alguien que unía a una dudosa ética profesional como editor un conocimiento muy completo de la intencionalidad realista con que de modo espontáneo y natural todos solemos leer, muy pronto se convirtió no solo en un gran éxito de ventas, sino también en una falsa realidad consistente, valga la paradoja. Así, se procede a identificar al destinatario de aquellas misivas en la persona de Noël de Chamilly, gentilhombre francés destinado en Lisboa allá por los años de 1660, cuando la expedición francesa contra los españoles, identificación que el propio interesado no desmentirá. Y ya en el siglo XIX se «descubre» a la anónima autora: Mariana de Alcoforado, muerta en el convento de la Concepción de Beja hacia 1723. Nacen así las famosas Lettres de la religieuse portugaise, cuya génesis y trayectoria como texto tan bien se compadece con el contenido del libro de Miguel Albero, con el estudio de Joaquín Álvarez Barrientos (2014) sobre la historia de las falsificaciones literarias españolas, o con el ensayo anteriormente publicado de Anthony Grafton (2001) que trata acerca de Falsarios y críticos. Creatividad e impostura en la tradición occidental.

No les atribuiremos a tales falsarios y mixtificadores la paternidad de esa forma posmoderna de falsedad que es la llamada posverdad, con sus bulos y patrañas, pero sí que sembraron el terreno para que floreciesen tan exuberantemente como lo están haciendo. Y siempre a beneficio del poder, y de los que lo detentan, sabedores de la capacidad del vulgo 
para comulgar con ruedas de molino. Un coetáneo de Maquiavelo, el cardenal Carlo Raffa, sentencíó: Populus vult decipi, ergo decipiatur. El pueblo quiere ser engañado; que lo sea.

Este es el escenario en que surge el nuevo concepto, interesante a la vez que preocupante, de la postverdad. De la fuerza de su impacto sobre la conciencia de los políticos e intelectuales, e incluso en el propio imaginario colectivo, da fe que el prestigioso diccionario inglés de Oxford lo distinguiese en 2016 con el título honorífico de palabra del año (en 2013 había sido seleccionada selfie, en 2014 vapear y en 2015, emoji).

Para el Oxford, post-truth es un adjetivo que se refiere a circunstancias que denotan que los hechos objetivos influyen menos en la formación de la opinión pública que los llamamientos a la emoción y a las creencias personales.

El origen del neologismo se atribuye a un autor teatral de origen serbio, Steve Tesich, que publicó en enero de 1992 un artículo en The Nation titulado «A Government of Lies» sobre lo que denominaba «el síndrome Watergate» para referirse a la equiparación entre verdad y malas noticias por parte del pueblo norteamericano que acabaría demandando al gobierno que lo protegiera contra ellas. Y concluía con una frase tan rotunda como la siguiente: «Fundamentalmente, nosotros, como pueblo libre, hemos decidido libremente que queremos vivir en una especie de mundo de la posverdad» («we, as a free people, have freely decided yhat we want to live in somo post-truth world》).

Esta actitud de la ciudadanía fue inmediatamente comprendida por Donald Reagan, que actuó en consecuencia, por ejemplo en el llamado escándalo Irán/Contra, amparado además por sus habilidades retóricas y escénicas de mediocre actor, pero recurriendo también a la coartada de un narcisismo relativista de base emocional, presente en la bizarra respuesta que dio cuando se demostró la verdad de aquel episodio. El presidente reconoció haberle negado al pueblo norteamericano que hubiese intercambiado armas por prisioneros, pero «mi corazón y mis mejores intenciones siguen diciéndome que es verdad, pero los hechos y las evidencias me dicen que no lo es».

Matthew d'Ancona (2017), que ha escrito sobre la nueva guerra contra la verdad y cómo combatirla, comenta a este respecto que este triunfo de lo visceral sobre lo racional, «de lo engañosamente simple sobre lo honestamente complicado» está en la esencia de la «cultura de la posverdad», para la que las respuestas no están en los hechos, en las pruebas, sino en el sentimiento de cada uno.

En 2004, el periodista estadounidense Eric Alterman calificó como «presidencia de la posverdad» la de George W. Bush. Y siempre en esta clave política, se reaviva la vigencia 
de la posverdad gracias a muchos de los argumentos de los políticos ingleses partidarios del llamado Brexit, y, sobre todo, de los tuits y peroratas de Donald Trump a lo largo de su campaña presidencial, e incluso después.

El empresario Arron Banks, que financió la campaña del Leave EU, explica su éxito porque los partidarios del Remain, se concentraron en presentar un hecho tras otro a favor de la permanencia del Reino Unido en la UE, cuando lo que había que hacer era «conectar con la gente de una forma emocional». Aunque fuese mintiendo que el gobierno británico transfería a Bruselas cada semana 350 millones de libras esterlinas, que de otro modo se podrían invertir en el Servicio nacional de salud, cuando en realidad eran cien millones menos, compensados además con importantes retornos presupuestarios. Una hora después de conocerse los resultados, Nigel Farage admitió que había engañado con aquella cifra supuestamente inyectable tras la salida de la Unión Europea en la Sanidad pública británica, y el eurodiputado brexiter Daniel Hannan reconoció que, en contra de lo predicado en campaña, para seguir teniendo acceso al mercado único era obligado permitir la entrada en el Reino Unido a los trabajadores comunitarios.

A este respecto, ha sentado cátedra un episodio protagonizado en 2004 por un asesor de Bush jr., Karl Rove, al que he hecho ya referencia. Cuando el periodista Ron Suskind lo estaba entrevistando, se topó con un planteamiento que lo dejó sin palabras. El «fontanero» del presidente desacreditó a la gente del común que vive inmersa en una realitybased community, y que por lo tanto creen a pies juntillas que la solución a los problemas vienen del estudio judicioso de una realidad discernible mediante un análisis razonado. con personas como él, estuviesen o no aposentadas en el ala oeste de la Casa Blanca. Pero según Rove, los happy few del ala oeste de la Casa Blanca sabían que el mundo ya no funcionaba así: "That's not the way the world really woks anymore». Porque «nosotros somos un imperio, y cuando actuamos, creamos nuestra propia realidad». Y no faltó una última confidencia de perdonavidas, cuando Rove le dice a Suskind que mientras él y gente como él se dedicaban a estudiar estas realidades judiciosamente, ellos (Bush y los suyos) «estamos nuevamente actuando, creando nuevas realidades que tendréis que estudiar también luego» (We're history's actors... and you, all of you, will be left to just study what we do).

Esta prepotencia de los «actores de la historia» frente a los curritos y piernas que todavía vivimos en una comunidad-basada-en-la-realidad reaparecerá potenciada al máximo con Trump, cuyos «fontaneros» se atreven incluso a redefinir el concepto de verdad. Así lo hace Stephen Colbert con la acuñación neologística de truthiness, referida a los fenómenos que 
parecen ciertos aunque no se basen en hechos, en realidades, en evidencias empíricas. Para el éxito de lo cual es imprescindible el abandono del pensamiento racional a favor del emocional. Y, por supuesto, la estupidez humana.

Por cierto, muchos «liberales» norteamericanos -denominación allí de los progresistas, izquierdista, incluso socialistas- han adoptado ese rubro para referirse a sí mismos con orgullo: reality-based community. Comunidad opuesta a los que abrazan la posverdad, a quienes optan por el reemplazo de la consideración exacta de la realidad por las pulsiones emocionales, ideológicas o religiosas, propias de la faith-based community. Con buen criterio, Christian Salmon (2007) concluye que, desafortunadamente, dirigentes de la primera potencia mundial como los mencionados arrumban no solo con la llamada realpolitik de la guerra fría, sino con el realismo puro y duro, para crear (e imponer) su propia realidad, practicando una especie de realpolitik de la ficción.

Muy pronto, tras la aparición del neologismo en el artículo de Steve Tesich, Ralph Keyes (2004) se atrevió ya a hablar de the post-truth era en un libro de gran éxito que trataba de la deshonestidad y el engaño en la vida contemporánea.

Me interesa especialmente subrayar que para este autor el germen de la posverdad estuvo en los medios universitarios norteamericanos. En ellos triunfó a finales del siglo XX el relativismo posmoderno, por la influencia de pensadores, sobre todo franceses, discípulos tardíos de Nietzsche y de Heidegger. Lo sorprendente del caso es que, lejos de quedar encerradas en las torres de marfil de los campus, estas reflexiones escépticas acerca de la verdad dieron el salto a ámbitos en principio tan blindados contra los juegos frívolos con las cosas más serias como el de la Justicia o las Iglesias.

En el Evangelio de San Juan (18: 37-38) leemos que cuando Jesús le dijo a Poncio Pilato «Yo para esto he venido al mundo, para dar testimonio de la verdad; todo el que es de la verdad oye mi voz», el prefecto romano de Judea le respondió: «¿ Y qué es la verdad?». Esa interrogante ha cobrado nuevos bríos en la Posmodernidad, inspirada casi siempre por uno de los filósofos más influyentes del siglo XIX, Friedrich Wilhelm Nietzsche. La posición extrema a este respecto es la de negación, simplemente, de la existencia de una verdad objetiva. Otras opciones apuntan más bien hacia el relativismo extremo: hay tantas verdades cuantos sujetos se preguntan por ella. Posición que se suele mencionar aludiendo al llamado «efecto Rashomon», inspirado por el título del filme que el cineasta Akira Kurosawa filmó en 1950 sobre relatos del escritor Akutagawa. La anécdota central recogida en el guion es el asesinato en el Japón medieval de un samurái y la violación de su esposa, sucesos trágicos de 
los que dan versiones distintas varios testigos y las propias víctimas a través de un médium. En ciencias sociales, incluso en el ámbito jurídico, se alude con tal expresión a la variabilidad de percepciones que sobre una misma realidad pueden darse desde perspectivas distintas, ninguna de las cuales merece ser tomada como totalmente falsa, pero tampoco como decididamente cierta.

La película incluye una conversación de tintes filosóficos entre un monje, un peregrino y un leñador que se guarecen de una fuerte tormenta en unas ruinas y aprovechan para comentar aquel episodio luctuoso, cuyos detalles inspiran sus reflexiones sobre la naturaleza de las acciones humanas y sobre la verdad. Lo que, en la tradición del pensamiento occidental, ocupa un espacio privilegiado en la Metafísica de Aristóteles en el siglo IV a. d. C.

El filósofo de Estagira se muestra ya muy crítico con las ideas relativistas de tradición escéptica, según las cuales nunca se podría decir «esto es verdad», sino siempre «es verdad para este», de modo que necesariamente se «hacen todas las cosas relativas, relativas a la opinión y a la sensación, de modo que nada hubo ni habrá sin alguien que haya opinado primero». Frente a tal aporía, Aristóteles responde con la expresión de un pensamiento que puede parecer hoy por hoy minimalista, un tanto tautológico, pero eficaz contra las alambicadas oscuridades deconstructivistas y posnietzscheanas: «Falso es, en efecto, decir que lo que es, no es, y que lo que no es, es; verdadero, que lo que es, es, y lo que no es, no es».

Este principio básico de correspondencia entre la realidad y el intelecto, que incluye también la expresión, va de Aristóteles a pensadores hebraicos como Isaac Israeli ben Solomon o musulmanes como Avicena, y se plasma en la fórmula escolástica que Tomás de Aquino acuña como adequatio rei et intellectus. Y llega hasta la filosofía ilustrada y racionalista de Kant, para quien la verdad consistía también en el acuerdo del conocimiento con su objeto. Hasta tal punto llega su creencia en la verdad que, en contra de los planteamientos posteriores de Nietzsche que enseguida comento, para el filósofo de Königsberg someterse a ella es un imperativo categórico de las personas. En su ensayo sobre «un presunto derecho de mentir por filantropía», tema reactivado por Benjamin Constant en la continuidad de una propuesta antigua que venía de Platón, Kant (1793) confirma que «la veracidad en las declaraciones que no pueden eludirse es un deber formal del hombre para con cualquier otro, por grave que sea el perjuicio que para él o para el otro pueda seguirse de ellas». La vigencia de esta firmeza llega hasta una intelectual argentina admirable, Victoria Ocampo, que después de haber dado con sus huesos en las cárceles de Perón, escribe en su revista Sur, en 1955, el 
artículo «La hora de la verdad» donde habla de la exigencia de transmitir «al mayor número posible de hombres» que con sus palabras y sus actos respondan a este principio: «la verdad es una tarea que nos incumbe. Es tarea de los intelectuales, de los educadores».

La continuidad de esta línea de pensamiento sobre la verdad desde los griegos hasta el Siglo de las Luces se rompe, como acabo de adelantar, con Friedrick Nietzsche, quien, en las antípodas filosóficas de Immanuel Kant, dedica en 1873 todo un ensayo filosófico a «la verdad y la mentira en sentido extramoral». Comienza mostrándose sorprendido por el «misterioso impulso» hacia la verdad que existe generalizadamente. Pero la verdad no es en modo alguno un concepto absoluto, sino funcional; no hay una verdad «esencial» sino un pacto entre individuos a través de las convenciones aportadas por «el poder legislativo del lenguaje» para convenir una «designación de las cosas uniformemente válida y obligatoria» que incluya el contraste entre verdad y mentira.

El mentiroso es rechazado no tanto por ser un falsario como por no respetar las convenciones, las reglas del juego. No detestamos, según Nietzsche (1903), «en rigor el embuste, sino las consecuencias perniciosas, hostiles, de ciertas clases de embustes». Deseamos la verdad por razón de sus «consecuencias agradables», «aquellas que mantienen la vida»; somos indiferentes al «conocimiento puro y sin consecuencias» y rechazamos sin más «las verdades susceptibles de efectos perjudiciales o destructivos».

El filósofo alemán añade otro elemento en su argumentación que está en la base de la Deconstrucción de Jacques Derrida. Me refiero a la desconfianza hacia las palabras: ¿Es el lenguaje la expresión adecuada de todas las realidades? El que haya tantas lenguas es una prueba más de que con las palabras «jamás se llega a la verdad ni a una expresión adecuada». La «cosa en sí», «la verdad pura, sin consecuencias» es, por tanto, «totalmente inalcanzable». Resulta insostenible postular que la verdad es decisiva en la génesis del lenguaje: «Creemos saber algo de las cosas mismas cuando hablamos de árboles, colores, nieve y flores y no poseemos, sin embargo, más que metáforas de las cosas que no corresponden en absoluto a las esencias primitivas». El origen del lenguaje no sigue un proceso lógico, e incluso los científicos y filósofos que buscan la verdad trabajan con materiales y procedimientos que en ningún caso apuntan hacia «la esencia de las cosas».

El error de partida lo encuentra Nietzsche en la propuesta del sofista Protágoras, que dio título a uno de los diálogos de Platón: el Hombre como medida de todas las cosas; «de las que son, en cuanto son; y de las que no son en cuanto no son». Sus escritos sirven de altavoz a una proclama metafórica, que se resume en una frase ligada definitivamente al 
filósofo alemán pero explicable por el triunfo del racionalismo laicista de las Luces: la muerte de Dios. Pero será uno de los discípulos no directos de Nietzsche, Michel Foucault (1966), que tanto contribuyó a crear la «cultura» de la posmodernidad junto a Derrida, Lacan, Deleuze, etc., el que reforzará aquel rechazo a la idea de Protágoras proclamando también «la muerte del hombre».

Diecinueve siglos después de Poncio Pilato, el autor de Así habló Zaratustra se hace la misma pregunta: ¿Qué es la verdad? Y responde de este tenor: «Una hueste en movimiento de metáforas, metonimias, antropomorfismo, en resumidas cuentas, una suma de relaciones humanas que han sido realzadas, extrapoladas y adornadas poética y retóricamente y que, después de un prolongado uso, un pueblo considera firmes, canónicas y vinculantes; las verdades son ilusiones de las que se ha olvidado que lo son; metáforas que se han vuelto gastadas y sin fuerza sensible, monedas que han perdido su troquelado y no son ahora ya consideradas como monedas, sino como metal».

De la influencia de este nihilismo nietzscheano en el pensamiento del siglo xx y de la Posmodernidad tenemos muchas pruebas; su impronta llegó incluso a teóricos de la literatura y de la comunicación como el canadiense Northrop Frye (1971) en su tesis del «mito de la incumbencia». Para él, también, la verdad y la realidad no se relacionan directamente con el razonamiento y la evidencia, sino que se establecen socialmente para mantener la unidad de la tribu a través de las palabras: «Para la incumbencia, verdad es lo que la sociedad hace y cree en respuesta a la autoridad; y la creencia, en la medida en que se verbaliza, es una declaración de la voluntad de participar en un mito de la incumbencia».

Y yo me pregunto a mi vez: ¿qué distancia hay entre la definición de Nietzsche o la incumbencia de Northrop Frye y la posverdad?

El novelista austríaco de origen judío Joseph Roth (2020) -al que no confundiremos con Philip, el autor de La mancha humana, que trata sobre la corrección política- publicó en 1932 La marcha Radetzky, una impresionante crónica novelada del desmoronamiento de la sociedad austrohúngara a raíz de la primera gran guerra acaecida entre 1914 y 1918 . Me parece útil traerla ahora a colación por el contraste que en ella se da ya entre la gente del común, perteneciente a la «comunidad basada en la realidad», y quienes entonces hacían (o pensaban que hacían) la Historia, en este caso el emperador Francisco José I y su corte.

El protagonista inicial de La marcha Raderky es un súbdito esloveno del emperador, un modesto campesino de Sipolje, que en la batalla de Solferino interpuso su cuerpo para evitar que una bala francoitaliana alcanzase a Francisco José. Ello le acarreó la rotura de la 
clavícula, pero también, consumada la derrota austrohúngara, el ascenso militar, la Orden de María Teresa y un título nobiliario. A partir de entonces sería el honorable capitán Joseph Trotta von Sipolje.

Un día, hojeando el libro de lectura escolar de su hijo de cinco años Trotta se encuentra con un relato del grave peligro que el emperador había pasado en aquella batalla. Enzarzado en un lance terrible con la caballería enemiga, en el que se había visto mezclado por su furor guerrero, la lanza enemiga dirigida contra él atravesó el pecho de «un jovencísimo teniente a lomos de un alazán bañado en sudor», y aquel «joven héroe» se convertiría así por mérito propio en noble laureado.

La reacción de Trotta es inmediata: «-jPero si es todo mentira». Y su esposa, al ver cómo arroja el libro escolar al suelo, replica: «-Es para niños». Lo mismo le dice el notario al que acude con su protesta indignada: «Todos los hechos históricos se representan de otra manera para enseñarlos en la escuela (...) Los niños necesitan ejemplos que ellos entiendan (...) La verdad ya la descubren más adelante».

Estas le parecen al Trotta respuestas de mal pagador, y convertido en «Caballero de la Verdad», comienza un «calvario» para restituirla. No contento con las respuestas del ministro de cultura y educación, solicita entrevista con el propio Emperador, que lo recibe y le aconseja: «Claro que ninguno de los dos salimos mal parados... ¡Déjelo estar, hombre». Tampoco convence a Trotta esta solución. Para él, de lo que se trataba era de una mentira. Y en consecuencia, solicita licencia del ejército, tras lo cual, para amainar las ínfulas de este Caballero de la Verdad, se le confiere el título de barón.

Trotta pertenecía a una reality based community. El emperador, obviamente, no- Como escribe Roth, «veía ponerse el sol en su imperio, pero no decía nada». Y, sobre todo, «había vivido el tiempo suficiente como para saber que decir la verdad es una tontería. Dejaba que la gente viviera feliz en sus errores y creía en la pervivencia de su mundo todavía menos que esos graciosos que contaban chistes sobre él por todo lo ancho de su imperio».

The New York Times reveló en su día que los tuits que Trump publicó en las primeras semanas tras su entrada en la Casa Blanca, el 20 de enero de 2017, propalaban falsedades en noventa y nueve casos. Por ejemplo, que él era el hombre que más veces había ocupado la portada de la revista Time. Mentía al decir que había sido en 14 o 15 ocasiones, cuando fueron exactamente once. El presidente Nixon llegó a aparecer nada más y nada menos que en 55 portadas. Y según el blog de verificación de datos de The Washington Post, en 466 días de inquilino del despacho oval, Donald Trump profirió 3.000 mentiras, lo que representa todo 
un récord: una media de 6,5 afirmaciones diarias que no eran ciertas. A los 928 días, la misma fuente, el factchecker del Post documentaba ya 12.019 afirmaciones falsas, trece bulos por día propagados a través de los tuits presidenciales. Se acredita también que siete de cada diez ciudadanos ya no creían a Trump, de ellos seis de cada diez republicanos. Ya en plena campaña electoral, entrevistado por el periodista conservador Hugh Hewitt, el entonces candidato presidencial se había ratificado en su temeraria y manifiestamente falsa afirmación de que Barak Obama había sido el creador del Estado Islámico, y de que Hillary Clinton era la cofundadora del ISIS.

En septiembre de 2020 Holden Thorp, editor jefe de Science, la revista científica de referencia internacional, publicó un editorial titulado «Trump mintió sobre la ciencia» acusando al presidente de engañar abierta y deliberadamente desde febrero de ese año sobre la gravedad de la crisis provocada por la COVID-19, desautorizando a los investigadores y provocando la pérdida de muchas vidas.

La comunidad científica no puede olvidar que en abril de 2020, en una comparecencia en la Casa Blanca acerca de la pandemia sugirió que los médicos deberían estudiar su idea de que ingerir o inyectarse lejía o «golpear el cuerpo con una luz tremenda, ultravioleta o simplemente muy potente» podría ser una buena solución para los afectados por el coronavirus. En otoño de ese mismo año el famoso periodista Bob Woodward, en su libro de conversaciones con Trump titulado Rage, revela que desde febrero, al menos, el presidente sabía de la letalidad de la peste, pero en sus ruedas de prensa afirmaba que «prácticamente lo hemos parado», «un día desaparecerá, como un milagro» y que «nada se cierra por la gripe». Se hartó de afirmar que la tasa de mortalidad era más baja que en casi todo el mundo, cuando los Estados Unidos ocupaba el décimo lugar entre los veinte países más afectados, y el tercero en cuanto a la tasa de muertos por cada 100.000 personas según los datos de la Universidad Johns Hopkins. El 2 de octubre de 2020, finalmente, Donald Trump anunció en la red que él mismo y su esposa Melanie habían dado positivo en los análisis para diagnosticar el COVID-19, que iniciaban su cuarentena y que We will get through this TOGHETER! (sic).

Nada sorprendente, por otra parte, todo esto en quien antes de su encumbramiento, en 2014, se había hecho eco de teorías negacionistas como las del doctor inglés Andrew Wakelfield que relacionaba las vacunas con el autismo. Las diatribas de Wakelfield provocaron un descenso de veinte puntos en los índices de vacunación, y en 2008 el sarampión volvió a ser endémico, pese a que el «informe McCormick» había demostrado 
científicamente que aquella conexión era un bulo. Lo que no impidió, según cuenta Mtthew d'Ancona, que una famosa de la televisión, Jenny McCarthy, madre de un niño afectado por el trastorno del espectro autista, negase esa refutación basándose en su «instinto materno» y aduciendo que «mi ciencia se llama Evan y está en casa» y «yo me licencié en la Universidad de Google»

En septiembre de 2019 Donald Trump se enfrentó con la NOAA (Administración Nacional Oceánica y Atmosférica, el servicio meteorológico norteamericano) cuando anunció en un tuit que el huracán Dorian iba a cebarse sobre todo en el Estado de Alabama, lo que provocó gran inquietud entre la población. Era domingo, y los científicos de la NOAA con sede en la Birmingham norteamericana se las vieron y desearon para tranquilizar a la ciudadanía, pues los datos no indicaban que Dorian fuese a pasar por allí. El presidente presionó, sin embargo, al servicio para que falsificaran un mapa del huracán, ajustándolo a su bulo.

Con anterioridad, poco después de su toma de posesión, en febrero de 2017 el flamante presidente provocó un incidente diplomático con Suecia, después de haber hecho referencia, en el transcurso de un mitin en Florida, a «lo que está pasando» en el país escandinavo por culpa de la relajada política migratoria de sus autoridades, errónea actitud del gobierno sueco que consideraba relacionable con los ataques terroristas en varios lugares de Europa.

Hasta que el propio Trump lo confirmó en un tuit, la única explicación que los periodistas fueron capaces de encontrar para el episodio, motivo más que justificado motivo para una protesta formal de la legación sueca en Washington, fue la hipótesis de que aquella declaración venía de una reciente emisión del canal conservador Fox. En efecto, en el programa 'Tucker Carlson Tonight' se incluyó una entrevista con el director y productor estadounidense Ami Horowitz, quien vinculó la llegada de inmigrantes a Suecia con un incremento del crimen. Trump lo había visto el día anterior y eso le inspiró el bulo: «Ves lo que está pasando en Alemania. Ves lo que está pasando la pasada noche en Suecia. ¡Suecia! ¿Quién podría creérselo? Suecia. Han acogido en grandes números. Están teniendo problemas como nunca pensaron que fuera posible». Y como siguió hablando de lugares donde había habido atentados terroristas, el auditorio creyó que se acababa de producir otro. En consecuencia, la embajada se dirigió al Departamento de Estado estadounidense para aclarar a qué se refería el Presidente. Y ante la prensa internacional, los portavoces de la 
política exterior de la primera potencia mundial declinaron pronunciarse al respecto porque su política era «no comentar comunicaciones diplomáticas privadas».

Si se quisiera echar un capote a Trump podría argumentarse que en definitiva se trataba de una equivocación, humanamente comprensible. Pero no fue así, sino un caso arquetípico de posverdad: la propagación de un bulo con un propósito decidido, agitar los bajos instintos de los estadounidenses contra los emigrantes, especialmente contra los latinos, precisamente en el momento en que el presidente estaba prometiendo construir un muro en la frontera del sur que ipagarían los propios mexicanos!

El viernes 24 de marzo de 2017 Lawrence Douglas publicó en The Guardian un espléndido comentario a la entrevista que el día anterior Time Magaz̧ine le había hecho al presidente, caracterizable por ofrecer una vertiginosa exhibición de lo que este prestigioso escritor y catedrático en Amherst College ha dado en denominar con ingenio Trumpspeak. Fundamentalmente en lo que se refiere a la mentira y a la verdad, el idiolecto trumpiano se distingue por una serie de rasgos inconfundibles. El presidente nunca puede ser acusado de mentir si se limita a repetir declaraciones de otros. En su discurso, la verdad no es fáctica, sino imaginística. Y la creencia en algo es indicio y garantía de verdad. Esta no posee de suyo una entidad y un valor independiente, sino que tales valores deben medirse exclusivamente por los efectos de la enunciación. Todo ello, amparado por el axioma de que el que habla es presidente, y sus contradictores no.

Obviamente, la post-truth se nutre básicamente de las llamadas fake-news, nuestros bulos, falsedades difundidas a propósito para desinformar a la ciudadanía con el designio de obtener réditos económicos o políticos. Muy famoso se ha hecho, a este respecto, el argumento de una funcionaria de la Casa Blanca, que desautorizaba las críticas generalizadas que provocó la declaración del portavoz del Presidente Trump en el sentido de que su toma de posesión había sido la más concurrida de la historia. La asesora Conway adujo que, en contra de las fotografías, videos y crónicas, por ejemplo, de cuando Barak Obama accedió a la primera magistratura de su país en olor de multitudes, el equipo de comunicación de Donald Trump manejaba «hechos alternativos». Alternativos a la verdad factual, se entiende. Verdaderas «fake news», noticias falsas, o mejor «falseadas», que inevitablemente nos hacen recordar a aquel genio malvado de la comunicación que fue el filólogo Joseph Goebbels, ministro de propaganda de Hitler, para quien el asunto era muy simple: una mentira repetida adecuadamente mil veces se convierte en verdad. 
Cierto es que la mentira forma parte de los recursos propios de la práctica política, como de manera difícilmente superable Nicolás Maquiavelo reflejó en El Príncipe. En la misma línea, según Hannah Arendt, el «estar en guerra con la verdad» va implícito en la naturaleza de la política, definida ya en su día por Benjamin Disraeli como «el arte de gobernar a la humanidad mediante el engaño». Igualmente afirma el florentino otra evidencia que sigue vigente: la de la ilimitada credulidad de los humanos, potenciada a veces por la simple estulticia. Y sobre estos mismos asuntos de la verdad, la mentira y el engaño trata también un siglo más tarde nuestro Baltasar Gracián (2011) a lo largo de todas sus obras, pero especialmente en El Hérore, El Politico y El Discreto, publicadas respectivamente en 1637, 1640 y 1646.

Su Oráculo manual y arte de prudencia, obra de 1647, se convirtió en un gran éxito en plena posmodernidad. En 1992 ocupó el primer puesto en la lista de los libros más vendidos en el apartado de «Nonfiction/General» del Washinton Post. Con el título de The Art of Wordly Wisdom: a Pocket Oracle miles de ejemplares fueron utilizados como prontuario de autoayuda para ejecutivos. Pero será en su Agudeza y arte de ingenio publicada un año después donde Gracián, con la sentenciosidad conceptista que lo hizo un escritor irrepetible, roza ya premonitoriamente el terreno de la posverdad. La Agudeza -la perspicacia- hecha personaje habla en primera persona a la Verdad, que se ve «despreciada y aun perseguida», lo que tiene su explicación lógica porque «no hay bocado más amargo que una verdad desnuda». Pero para resolver este grave problema «inventaron los sagaces médicos del ánimo el arte de dorar las verdades, de azucarar los desengaños». Y concluye la Agudeza con una propuesta de tanta actualidad como la siguiente: «Quiero decir (y observadme bien esta lición, estimadme este consejo) que os hagáis política; vestíos al uso del mismo Engaño, disfrazaos con sus mismos arreos, que con eso yo os aseguro el remedio, y aun el vencimiento».

En términos de la Pragmática lingüística, aquella disciplina que trata del funcionamiento del discurso en relación tanto al que lo pronuncia como al que lo recibe, y al contexto de ambos, disciplina que el político y catedrático Enrique Tierno Galván conocía muy bien pues no en vano tradujo del alemán el Tractatus Logico-philosoficus de Ludwig Witgenstein, las afirmaciones de Maquiavelo acerca de la mendacidad en política equivale a decir que los actos ilocutivos producidos en un mitin son aserciones exentas del requisito de la verificación.

Con toda sinceridad he de decir que no me parece muy probable que Donald Trump haya sido asiduo lector de Baltasar Gracián ni de los filósofos franceses Jacques 
Derrida y Michel Foucault (y lo dudo también en el caso de Maquiavelo). Pero es evidente la conexión entre este clima de pensamiento posmoderno por ellos propiciado, que tuvo mayor arraigo en los campus universitarios norteamericanos que en Europa, y la posverdad. La llamada deconstrucción, un signo más de la sociedad líquida, dejó el terreno abonado para el triunfo de la postruth, y a todo ello contribuye también el éxito arrollador de la llamada inteligencia emocional, que exacerbada y banalizada puede conducir a la quiebra de la racionalidad. Porque es cierto que la Deconstrucción niega a la Literatura y en general al lenguaje la posesión de sentido. Esto equivale a una manifestación radical en contra de una «hermenéutica positiva» como la representada a principios del siglo XIX por Friedrich Schleirmacher, para la que, hiperbólicamente, el sentido de un texto es exactamente el que el autor quiso darle. Semejante postura resulta también equivocada. El libro significa, de cierto, lo que el lector quiere que signifique, pero desde este relativismo hermenéutico, que la Fenomenología explica por la evidencia de que la obra literaria es un esquema que debe ser «rellenado» por el lector en sus lagunas, en sus «lugares de indeterminación», todavía queda mucha distancia para llegar a una «hermenéutica negativa», que niega a la Literatura, y por ende a todo enunciado estable, la capacidad retransmitir sentido.

Aparte de los bulos característicos de Trump y de los «brexiters», no deja de denunciarse constantemente la intensificación de las campañas desinformativas contra la ciudadanía en otros países como Hungría, Turquía o Rusia. Por no hablar, entre nosotros, del procès.

Es bien conocida la incidencia de manipulaciones de la opinión pública de terceros países por parte de instancias oficiales rusas con el fin de influir, por caso, en el resultado de importantes citas electorales, incluidas los comicios presidenciales de Francia o los Estados Unidos. Su «tecnología políticaV cuenta con plataformas como la identificada como APT28, controlada por el GRU, la agencia de inteligencia militar rusa, que emplea estrategias digitales para confundir y sabotear a quienes consideran enemigos, en general los países europeos y los Estados Unidos. En 2014 el diario británico The Guardian detectó quinientos comentarios hostiles a sus páginas procedentes de troles prorrusos.

Así por ejemplo, Peter Pomerantsen (2015) afirma desde el principio de un interesante libro para nuestro tema que nada es verdad y todo es posible en la era de Putin, tomando nota de su experiencia como periodista y productor televisivo en Rusia entre 2006 y 2010. Para él, todos los «reality-showsV rusos están «guionizadosV, del mismo modo que el Kremlin programa la actividad parlamentaria de la Duma y los resultados de las elecciones. 
Sobre la convicción presidencial de que la televisión es la única fuerza capaz de gobernar y unir a la nación, la torre Ostankino desde la que se emite es «el ariete de propaganda del Kremlin». Propaganda que prolonga los procedimientos soviéticos, pero los fusiona muy hábilmente con la apoteosis del espectáculo predominante en las cadenas europeas y americanas. Las noticias están programadas también como el incienso que bendice las acciones del presidente, y los efluvios de su nube adormecen la racionalidad de los telespectadores.

El entramado de una operación tan sumamente trascendente no puede dejar de tener su cerebro pensante y su mano dura ejecutora: Vladislav Surkov, al que la London Review of Books motejó como «el Rasputín de Putin». Según Pomerantsen, es un maestro en la «cultura de la simulación» que lo devora todo en la «nueva Rusia». Fue uno de los primeros funcionarios rusos objeto de sanción por parte de Europa y los Estados Unidos por su orquestación mediática cuando la anexión de Crimea en 2014. Intensificó entonces el relato (en el próximo capítulo trataremos de las patrañas como complemento perfecto de los bulos) del odio occidental contra los rusos, con imágenes de mujeres que decían haber sido agraviadas por extranjeros, y que en realidad eran extras disfrazadas de testigos oculares de sevicias y humillaciones. Por supuesto: en este conflicto entre Rusia y los Demás, solo Putin puede salvar al país. La nueva «tecnología política» puesta al servicio de este proyecto pasa fundamentalmente por la torre Ostaankino. Y Pomerantsen se pregunta: si la televisión oficial puede mentir tanto y salirse siempre con la suya, ¿no significa esto que tienen verdadero poder, poder para definir lo que es cierto y lo que no lo es? El poder de Putin reside en que puede decir lo que quiera cuando quiera, independientemente de los hechos, como ocurrió cuando la agresión a Ucrania. La periodista Masha Gessen, comentando este episodio, sentenció con una frase rotunda: «Es presidente de su país y rey de la realidad». También Umberto Eco, debelador del poder de Berlusconi, escribió valientes páginas en el diario L'Epresso sobre el «populismo mediático», que en un próximo capítulo tendré que relacionar con el concepto posmoderno de una posdemocracia donde reina la posverdad.

Pero no menos interesantes que los datos apuntados a propósito de la personalidad y la trayectoria de Vladislav Surkov es de destacar las influencia que sobre él ejerce el pensamiento de Jacques Derrida. En noviembre de 2017 la web rusa RT publicó un ensayo de Surkov que lo acredita. En él hace suyas las ideas del filósofo francés acerca de la escasa fiabilidad del lenguaje y la quiebra existente entre las palabras y su significado, de lo que deduce que las nociones de veracidad y transparencia, fundamentales para toda política recta, 
no dejan de ser ingenuidades y simplezas. Surkov rechaza la existencia de una realidad objetiva; comparte con la deconstrucción el convencimiento de que no hay «hors texte», nada más allá del propio discurso enunciado. Y, en consecuencia, el argumento de «hechos alternativos» es tan legítimo para Trump como para Putin.

Los medios audiovisuales y la red de redes tienen hoy en sus manos, con redoblada intensidad, la capacidad de crear realidades: guerras y paces, héroes y villanos, presencias y ausencias. Por ello no es del todo descabellada aquella pregunta: ¿ustedes creen realmente que los astronautas norteamericanos llegaron a la luna? El propio Jean Baudrillard (1991) escribiría un brillante ensayo sobre estos supuestos inspirándose para su título en la comedia de Giradoux: La guerre du Golfe n'a pas en lieu.

Se ha traducido de forma ingeniosa como documentira el término inglés mockumentary, neologismo inventado para designar los documentales ficticios. Y acaso el más brillante y famoso de todos tenga que ver con las dudas que, irónicamente, expresaba Braudillard. En 2002 en canal Arte France emitió el programa Opération Lune del director cinematográfico William Karel, que parte de una decisión tomada por el presidente Nixon a propósito de la misión del Apolo 11. Ante el temor de que la grabación real de la llegada del primer hombre a la luna fallase, se procede a rodar la escena en un estudio de cine bajo la dirección de Stanley Kubrick. Y como las acciones «reales» de Neil Armstrong aquel 20 de julio de 1969 no parecieron lo suficientemente satisfactorias, las que se emitieron fueron las rodadas, fraude que los servicios secretos soviéticos denunciaron, lo que obliga a la Casa Blanca a eliminar a todo el equipo de rodaje menos el director de 2001: una odisea en el espacio. Solo al final se revela que todo forma parte de una documentira, para cuya credibilidad y veroficción se había recurrido previamente a una larga serie de entrevistas «guionizadas» con actores, o debidamente manipuladas con personajes reales de la política como Donald Rumsfeld, Henry Kissinger o Alexander Haig.

Desde mucho antes, esa facultad de poiesis, más que de mimesis de la realidad la tenían los periódicos, y la siguen manteniendo. Y desde siempre ha sido ésta una prerrogativa de la palabra literaria. Pero después de los vaticinios de Marshall McLuhan, la imagen se ha convertido en el instrumento privilegiado de esta transición entre el re-producir la realidad y, simplemente, producirla. Un artista de la técnica inventada por Niépce y Daguerre, Joan Fontcuberta, asegura que «el buen fotógrafo es el que miente bien la verdad» que su cámara capta. Se puede hablar, así, de la fotografía como veroficción, un neologismo todavía no aceptado por la RAE pero que cumple una función semántica que acabará siendo reconocida. 
Siendo como es este asunto tan antiguo como la Humanidad, adquiere no obstante nuevas y preocupantes dimensiones en la era posmoderna que vivimos, con su invención de la llamada realidad virtual. Reflexionemos, como se ha hecho ya, en lo que de autocrítica o de palinodia tiene la severa admonición incluida por Jean Baudrillard (1994) en su ensayo Le crime parfait: «El verdadero escándalo es menos el atentado contra las costumbres que contra el principio de realidad». Autocrítica y palinodia porque este filósofo de la posmodernidad fallecido en 2007 se había empeñado, con el mismo afán destructivo de Foucault o Derrida, en demostrar que la tecnología audiovisual y las nuevas plataformas comunicativas han arrumbado de una vez por todas con nuestra facultad de discernir entre verdad y mentira, la historia y la fábula. Su argumento primordial era que vivimos en un mundo en el que la más alta función del signo es hacer desaparecer la realidad y enmascarar a la vez esa desaparición. De ahí mi interés por abordar, en homenaje a Rafael Núñez Ramos, tan preocupante asunto a partir de las relaciones entre literatura y política. 


\section{BIBLIOGRAFÍA}

Albero, Miguel (2020): La invasión de lo falso, Barcelona, Espasa.

Álvarez Barrientos, Joaquín (2014): El crimen de la escritura. Una historia de las falsificaciones literarias españolas, Madrid, Abada Editores.

Aristóteles (1994): Metafísica, introducción, traducción y notas de Tomás Calvo Martínez, Madrid, Editorial Gredos.

Baudrillard, Jean (1991): La guerra del Golfo no ha tenido lugar, Barcelona, Anagrama. Primera edición francesa, 1991.

Baudrillard, Jean (1994): Le crime parfait, París, Éditions Galilée.

Cannon, Lou (1991): President Reagan. The Role of a Lifetime, Nueva York, Simon \& Schuster.

Castelao, Alfonso R. (1999): Obras, tomo I, Vigo, Editorial Galaxia.

D’Ancona, Matthew (2019): Posverdad. La nueva guerra contra la verdady como combatirla. Madrid, Alianza Editorial. Primera edición inglesa, 2017.

Derrida, Jacques (1967): L,écriture et la différence, Paris, Du Seuil.

Derrida, Jacques (1978): De la gramatología, México, Siglo XXI (Segunda edición). Primera edición francesa, 1967.

Fontcuberta, Joan (2000): El beso de Judas. Fotografía y verdad, Barcelona, Gustavo Gili. Primera edición española, 1997.

Foucault, Michel (1966): Les mots et les choses: Une archeology des sciences humaines, Paris, Éditions Gallimard.

Foucault, Michel (2018): El orden del discurso, Madrid, Tusquets. Primera edición francesa, 1970.

Frye, Northrop (1986): El camino crítico. Ensayo sobre el contexto social de la crítica literaria, Madrid, Taurus. Primera edición, 1971.

Grafton, Anthony (2001): Falsarios y críticos. Creatividad e impostura en la tradición occidental, Barcelona, Editorial Crítica. Primera edición inglesa, 1990.

Kant, Immanuel (1993): Teoría y Práctica, Madrid, Tecnos. Primeras ediciones alemanas de 1793 y 1797.

Keyes, Ralph (2004): The Post-Truth Era. Dishonesty and Deception in Contemporary Life. New York, St. Martin's.

Lakoff, George (2019): No pienses en un elefante. Lenguaje y debate político, Barcelona, Ediciones Península. Primera edición inglesa, 2004. 
Levine, Timothy (2020): Duped. Truth-Default Theory and the Social Science of Lying and Deception.

Tuscaloosa, The University of Alabama Press.

McIntyre, Lee (2018): Post-Truth. Cambridge, MIT.

Nietzsche, Friedrich (2017): Sobre verdad y mentira en sentido extramoral y otros fragmentos de filosofía del conocimiento, Madrid, Tecnos. Primera edición alemana, 1903.

Pomerantsev, Peter (2017): La nueva Rusia. Nada es verdad y todo es posible en la era de Putin, Barcelona, RBA. Primera edición inglesa, 2015.

Roth, Joseph (2020): La marcha Radetzky, Madrid, Alianza Editorial. Primera edición alemana, 1932.

Salmon, Christian (2010): Storytelling. La máquina de fabricar historias y formatear las mentes, Barcelona, Península. Primera edición francesa, 2007.

Vargas Llosa, Mario (2012): La civilización del espectáculo, Madrid, Alfaguara.

Villanueva, Darío (2008): Las fábulas mentirosas. Lectura, realidad, ficción, Aguascalientes, Universidad Autónoma de Aguascalientes.

Villanueva, Darío $\left(2020^{3}\right)$ : Teorías del realismo literario, Madrid, Biblioteca Nueva. Primera edición española, 1992.

Villanueva, Darío (2021): Morderse la lengua. Corrección política y posverdad, Barcelona, Espasa. 
SOBRE EL AUTOR

\section{Darío Villanueva}

Catedrático de Teoría de la literatura y literatura comparada de la Universidad de Santiago de Compostela. Miembro de la Real Academia Española de la que ha sido Presidente.

Contact information: correo electrónico: dario.villanueva@usc.es 